\title{
The IL-1B Genetic Polymorphism Is Associated with Aspirin-Induced Peptic Ulcers in a Korean Ethnic Group
}

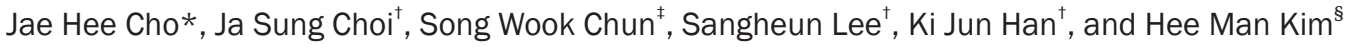 \\ *Division of Gastroenterology, Department of Internal Medicine, Gachon University Gil Medical Center, ${ }^{\dagger}$ Department of Internal Medicine, \\ International St. Mary's Hospital, Catholic Kwandong University College of Medicine, Incheon, ${ }^{\ddagger}$ Division of Gastroenterology, Department of \\ Internal Medicine, Myongji Hospital, Goyang, and ${ }^{s}$ Division of Gastroenterology and Hepatology, Department of Internal Medicine, Yonsei \\ University Wonju College of Medicine, Wonju, Korea
}

Background/Aims: Single nucleotide polymorphisms (SNPs) are associated with aspirin-induced peptic ulcers. However, SNPS of specific genes vary among races, and data regarding SNPs in the Korean population are scarce. In this study, we aimed to investigate the relationships between SNPs of the COX-1, IL-1 $\beta, I L-1 R N$, and TNF genes and aspirin-induced peptic ulcers, as pilot research in a Korean population. Methods: Patients who had been taking low-dose aspirin (100 mg) for at least 4 weeks were prospectively enrolled. DNA was extracted from whole blood, and DNA sequencing was subsequently performed. Results: A total of 48 patients were enrolled (23 peptic ulcer patients vs 25 nonulcer controls). Three exon SNPs (IL-1 $\beta$-581C/T [rs1143627], IL-1 $\beta$-1061C/ $\mathrm{T}$ [rs16944], and IL-1RN -1129 [rs4251961]) and one intron SNP (IL-1 $\beta$ IVS2+242C/T) were significantly different between the two groups. On the multivariate analysis after adjustments for age and sex, the CC/CT genotypes of IL-1 $\beta-581 \mathrm{C} /$ $\mathrm{T}$, and the $\mathrm{CT} / \mathrm{TT}$ genotypes of $\mathrm{IL}-1 \beta-1061 \mathrm{C} / \mathrm{T}$ were positively associated with aspirin-induced peptic ulcers (odds ratio [OR], 4.6, 95\% confidence interval [Cl], 1.054 to 20.303, $p=0.04$; OR, 4.6, 95\% Cl, 1.054 to 20.303, $p=0.04)$. Conclusions: The IL-1 $\beta-581 C / T$ and $I L-1 \beta-1061 C / T$ genotypes may be associated with low-dose aspirin-induced peptic ulcers in a Korean ethnic group. (Gut Liver 2016;10:362-368)

Key Words: Aspirin; Polymorphism, single nucleotide; Peptic ulcer

\section{INTRODUCTION}

Aspirin is used for the prevention of cardiovascular and cerebrovascular diseases worldwide. However, aspirin is also known to have adverse effects on the gastrointestinal (GI) tract including peptic ulcer disease and bleeding. The annual incidence of peptic ulcers induced by aspirin is approximately $5 \%$ to $10 \%,{ }^{1-3}$ and the prevalence is approximately $10 \%{ }^{2}$ The presence of peptic ulcers can induce a number of serious adverse effects including GI bleeding that may result in death in some patients.

There are a number of risk factors for the development of peptic ulcers secondary to aspirin use including advanced age, Helicobacter pylori infection, concomitant use of nonsteroidal anti-inflammatory drugs (NSAIDs), aspirin dose, and a past medical history of peptic ulcers. ${ }^{2,5}$ Additionally, genetic predisposition is also associated with aspirin-induced peptic ulcer. ${ }^{6-8}$ In order to prevent peptic ulcer in patients taking low-dose aspirin, concomitant use of a proton pump inhibitor is often initiated. However, this strategy does not help to identify patients with a high risk of developing peptic ulcers. Therefore, individual genetic susceptibility may be an important factor in identifying patients at highest risk for peptic ulcer.

Several studies have shown an association between single nucleotide polymorphisms (SNPs) of several genes and aspirininduced peptic ulcer. These include SNPS of the COX-1, CY$P 2 C 9, I L-1 \beta, I L-1 R N$, and TNF- $\alpha$ genes. ${ }^{9}$ However, there is racial diversity in these genes, and thus the significance of SNPs as related to specific diseases is also different among races.

We hypothesized that, if patients could be identified as having a genetic predisposition for peptic ulcer before starting aspirin therapy, the development of peptic ulcer could be prevented

\footnotetext{
Correspondence to: Hee Man Kim

Division of Gastroenterology and Hepatology, Department of Internal Medicine, Yonsei University Wonju College of Medicine, 20 Ilsan-ro, Wonju 26426, Korea

Tel: +82-33-741-1229, Fax: +82-33-741-1228, E-mail: loverkorea2009@gmail.com

Received on March 12, 2015. Revised on May 25, 2015. Accepted on July 16, 2015. Published online November 27,2015 pISSN 1976-2283 eISSN 2005-1212 http://dx.doi.org/10.5009/gnl15129

(c) This is an Open Access article distributed under the terms of the Creative Commons Attribution Non-Commercial License (http://creativecommons.org/licenses/by-nc/4.0) which permits unrestricted non-commercial use, distribution, and reproduction in any medium, provided the original work is properly cited.
} 
by concomitant use of proton pump inhibitors or alternative antiplatelet agents. Because SNPs of the $C O X-1, I L-1 \beta, I L-1 R N$, TNF genes, and SNPs specifically associated with peptic ulcer are still not well understood, we investigated the prevalence of SNPs of the $C O X-1, I L-1 \beta, I L-1 R N$, and TNF genes in Korean adults and evaluated the associations between these SNPs and aspirin-induced peptic ulcer in this population, as a pilot research.

\section{MATERIALS AND METHODS}

\section{Subjects}

From May 2011 to December 2012, we performed a prospective case-control study of DNA sequence analysis on 48 patients who took low-dose aspirin and underwent esophagogastroduodenoscopy (EGD). All subjects had been taking low-dose aspirin (100 mg) for at least 4 weeks prior to enrollment, and each subsequently underwent EGD at Myongji Hospital in Goyang, Korea. They were divided into two groups based on endoscopy results including a nonulcer control group $(n=25)$ with no evidence of peptic ulcer and a peptic ulcer group $(n=23)$ that showed evidence of gastric or duodenal ulcer. In this study, a peptic ulcer was defined as a mucosal defect $\geq 5 \mathrm{~mm}$ in diameter based on endoscopic findings. Exclusion criteria included history of peptic ulcer, history of NSAID or steroid use, history of clopidogrel use, history of upper GI surgery, pregnancy, chronic renal failure, history of proton pump inhibitor or $\mathrm{H}_{2}$ receptor blocker use, history of congenital disease, history of autoimmune disease, and malignant disease of the upper GI tract including esophageal or gastric cancer. Blood obtained from subjects was stored in ethylenediaminetetraacetic acid-containing tubes at $-40^{\circ} \mathrm{C}$ and was subsequently sent to a laboratory facility for genotyping. SNP data were compared between groups. Informed consent was obtained from all subjects. This study was approved by the Institutional Review Board (IRB number: 10076) at Myongji Hospital and all patients gave written informed consent to participate in this study.

\section{DNA sequencing}

Polymerase chain reaction (PCR) was used to amplify 11 fragments of the $I L-1 \beta$ gene, 10 fragments of the $I L-1 R N$ gene, 15 fragments of the $C O X-1$ gene, and eight fragments of the TNF gene. The final volume of the PCR was $10 \mu \mathrm{L}$, consisting of $10 \mathrm{ng}$ of DNA, $0.5 \mathrm{uM}$ of each primer pair, $0.25 \mathrm{mM}$ deoxyribonucleoside triphosphates, $3 \mathrm{mM} \mathrm{MgCl}_{2}, 1 \mu \mathrm{L} 1 \times$ reaction buffer, and 0.25 unit Taq DNA polymerase (Intron Biotechnology, Seongnam, Korea). The PCR conditions used were as follows: initial denaturation at $94^{\circ} \mathrm{C}$ for 5 minutes, followed by 35 cycles of denaturation at $94^{\circ} \mathrm{C}$ for 30 seconds, annealing at $60^{\circ} \mathrm{C}$ to $65^{\circ} \mathrm{C}$ for 30 seconds, initial extension at $72^{\circ} \mathrm{C}$ for 30 to 60 seconds, and final extension at $72^{\circ} \mathrm{C}$ for 10 minutes. The PCR products were purified using a MultiScreen 384-PCR filter plate
(Millipore, Billerica, MA, USA). The purified products were then sequenced using a BigDye Terminator cycle sequencing kit (Applied Biosystems, Foster City, CA, USA) and an ABI 3730xl automated sequencer (Applied Biosystems). The sequencing primers were the same as those used for PCR amplification. Mutation analyses were performed using Phred, Phrap, Consed, Polyphred 5.04 software (http://droog.gs.washington.edu/polyphred).

\section{Statistical analysis}

Genotype and allele frequencies were compared between groups using chi-square or Jonckheere-Terpstra test, as appropriate. Odds ratios (ORs) and 95\% confidence intervals (CIs) were estimated using multiple logistic regression with adjustments for age and sex in order to evaluate the significance of the associations between SNPs and disease status. Data analysis was performed using SAS software version 9.1.3 (SAS Inc., Cary, NC, USA). All statistical tests were two-tailed, and p-values $<0.05$ were considered to be statistically significant.

\section{RESULTS}

\section{Baseline characteristics}

Between January 2011 and January 2013, a total of 48 patients were enrolled in this study, including 23 subjects with peptic ulcer and 25 nonulcer control subjects (Table 1). The mean ages of the peptic ulcer group and nonulcer control group were $66.22 \pm 10.85$ years and $62.48 \pm 9.01$ years, respectively $(p=0.199)$. The percentages of male patients in the peptic ulcer group and nonulcer control group were $60.9 \%$ and $48 \%$, respectively ( $\mathrm{p}=0.371)$. On EGD examination, peptic ulcers were found to be located in the stomach (91.3\%) and duodenum (8.7\%). Thirteen patients (56.5\%) had a single ulcer and 10 patients (43.5\%) had multiple ulcers $(\geq 2)$.

Table 1. Baseline Characteristics of All Subjects $(n=48)$

\begin{tabular}{lccc}
\hline \multicolumn{1}{c}{ Characteristic } & $\begin{array}{c}\text { Peptic } \\
\text { ulcer }\end{array}$ & $\begin{array}{c}\text { Nonulcer } \\
\text { control }\end{array}$ & p-value \\
\hline No. of patients & $23(47.9)$ & $25(52.1)$ & - \\
Age, yr & $66.22 \pm 10.85$ & $62.48 \pm 9.01$ & 0.199 \\
Sex, male/female & $14 / 9$ & $12 / 13$ & 0.371 \\
Ulcer location & & & - \\
$\quad$ Gastric ulcer & $21(91.3)$ & - & - \\
$\quad$ Active or healing stage & 18 & - & \\
$\quad$ Scar & 5 & - & - \\
$\quad$ Duodenal ulcer & $2(8.7)$ & - & - \\
$\quad \begin{array}{l}\text { Active or healing stage } \\
\quad \text { Scar }\end{array}$ & 1 & - & - \\
Multiple ulcer $(\geq 2)$ & $10(43.5)$ & - & - \\
Helicobacter pylori infection & $6(26.1)$ & - & - \\
\hline
\end{tabular}

Data are presented as number (\%) or mean \pm SD. 


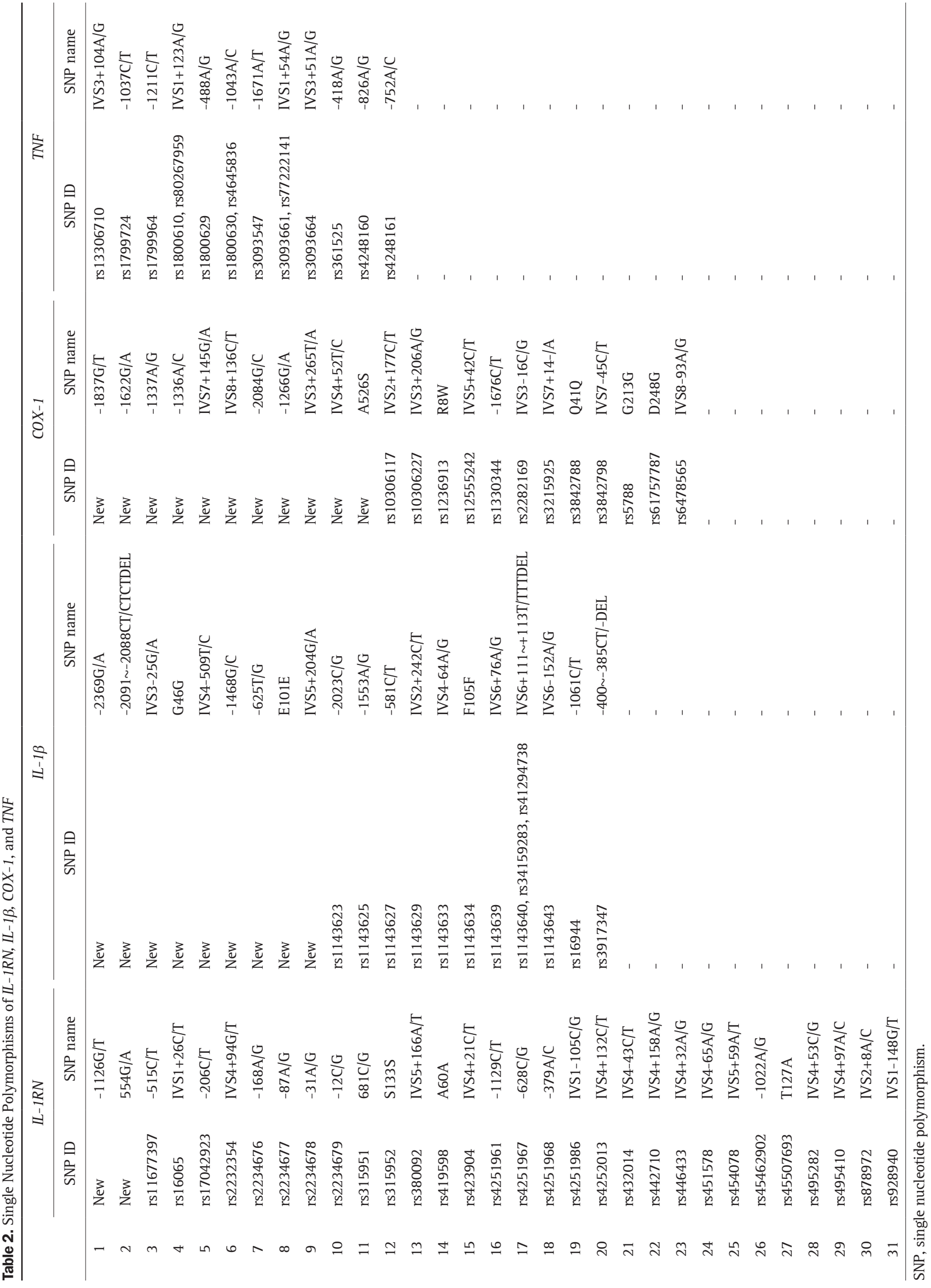




\section{SNPs of the COX-1, IL-1B, IL-1RN, and TNF genes}

All SNPs of the four genes identified in this study are shown in Table 2. The $I L-1 R N$ gene had 31 SNPs, of which two (-1126G/ $\mathrm{T}$ and 554G/A) were newly identified. The $I L-1 \beta$ gene had 22 SNPs, of which 9 (-2369G/A, -2091 -2088CT/CTCTDEL, IVS325G/A, G46G, IVS4-509T/C, -1468G/C, -625T/G, E101E, and IVS5+204G/A) were newly identified. The COX-1 gene had 23 SNPs, of which 11 (-1837G/T, -1622G/A, -1337A/G, -1336A/ C, IVS7+145G/A, and IVS8+136C/T) were newly identified. The TNF gene had 12 identified SNPs.

\section{Associations between SNPs and peptic ulcer}

Four SNPs had significantly different frequencies in the peptic ulcer and nonulcer control groups: IL-1RN -1129C/T (rs4251961), IL-1 $\beta$-581C/T (rs1143627), IL-1 $\beta$-1061C/T (rs16944), and IL-1 $\beta$ IVS2+242C/T (rs1143629). For IL-1 $\beta-581 \mathrm{C} / \mathrm{T}$, the TT genotype was less frequent in the peptic ulcer group than the nonulcer control group (13\% vs 44\%, $\mathrm{p}=0.018$ ) (Table 3 ). For $I L-1 \beta$ $-1061 \mathrm{C} / \mathrm{T}$, the CC genotype was less frequent in the peptic ulcer group than the nonulcer control group (13\% vs $44 \%, \mathrm{p}=0.018$ ). For IL-1 $\beta$ IVS $2+242 C / T$, the TT genotype was less frequent in the peptic ulcer group than the nonulcer control group (13\% vs $44 \%, p=0.018$ ). Finally, for $I L-1 R N-1129 \mathrm{C} / \mathrm{T}$, the TT genotype was more frequent in the peptic ulcer group than the nonulcer control group (96\% vs 68\%, $p=0.011$ ).

Logistic regression analysis for adjustment of age and sex was performed in three exon SNPs (Table 4). The IL-1 $\beta-581$ genotype was significantly associated with peptic ulcer. The CT and CC genotype had an OR of 4.625 (95\% CI, 1.054 to 20.303; $\mathrm{p}=0.042$ ) for the peptic ulcer group, as compared with the TT genotype. The $I L-1 \beta-1061$ genotype was also significantly associated with peptic ulcer, and the CT and TT genotypes had an OR of 4.625 (95\% CI, 1.054 to 20.303; p=0.042) for the peptic ulcer groups compared with the CC genotype. The $I L-1 R N-1129$ genotype was not associated with peptic ulcer after adjustment for age and gender. The CT and CC genotypes had an OR of 0.115 (95\% CI, 0.013 to 1.049 ; $p=0.055$ ) for the peptic ulcer group.

\section{DISCUSSION}

Our study is the first to investigate SNPs of the COX-1, $I L-1 \beta$, $I L-1 R N$, and TNF genes in Korean subjects, identifying 23, 22, 31, and 12 SNPs, respectively, including 22 novel SNPs. In addition, we aimed to reveal the significant associations between specific genotypes and aspirin-induced peptic ulcer disease. Of a total of 88 SNPs, two of the $I L-1 \beta$ gene and one of the $I L-1 R N$ gene were significantly associated with peptic ulcer. $C$ carriers of $I L-1 \beta-581$ and $T$ carriers of $I L-1 \beta-1061$ were significantly more frequently associated with peptic ulcer, and there was a trend for association between $\mathrm{T}$ carriers of IL-1RN -1129 and peptic ulcer, though this was not significant after adjustment for age and sex.

Aspirin irreversibly inhibits cyclooxygenase-1 $(\mathrm{COX}-1)$ in platelets. Genetic polymorphisms of the $C O X-1$ gene can affect aspirin-induced inhibition of prostaglandin synthesis, which

Table 3. Single Nucleotide Polymorphism Genotypes in the Peptic Ulcer Group and Nonulcer Control Group

\begin{tabular}{|c|c|c|c|c|c|c|}
\hline SNP & SNP ID & MAF & Peptic ulcer (n=23) & Nonulcer control $(n=25)$ & p-value & Functional consequence \\
\hline$I L-1 \beta-581 \mathrm{C} / \mathrm{T}$ & rs1143627 & 0.4479 & & & $0.0184^{*}$ & Upstream variant $2 \mathrm{~KB}$ \\
\hline $\mathrm{TT}$ & & & $3(13.04)$ & $11(44.0)$ & & \\
\hline CT & & & $15(65.22)$ & $10(40.0)$ & & \\
\hline $\mathrm{CC}$ & & & $5(21.74)$ & $4(16.0)$ & & \\
\hline IL-1 $\beta-1061 \mathrm{C} / \mathrm{T}$ & rs 16944 & 0.4479 & & & $0.0184^{*}$ & Upstream variant $2 \mathrm{~KB}$ \\
\hline $\mathrm{CC}$ & & & $3(13.04)$ & $11(44.0)$ & & \\
\hline CT & & & $15(65.22)$ & $10(40.0)$ & & \\
\hline TT & & & $5(21.74)$ & $4(16.0)$ & & \\
\hline IL- $1 \beta$ IVS $2+242 \mathrm{C} / \mathrm{T}$ & rs1143629 & 0.4583 & & & $0.0184^{*}$ & Intron variant \\
\hline $\mathrm{TT}$ & & & $3(13.04)$ & $11(44.0)$ & & \\
\hline CT & & & $15(65.22)$ & $9(36.0)$ & & \\
\hline $\mathrm{CC}$ & & & $5(21.74)$ & $5(20.0)$ & & \\
\hline$I L-1 R N-1129 \mathrm{C} / \mathrm{T}$ & rs4251961 & 0.1042 & & & $0.0116^{\dagger}$ & Upstream variant $2 \mathrm{~KB}$ \\
\hline TT & & & $22(95.7)$ & $17(68.0)$ & & \\
\hline $\mathrm{CT}$ & & & $1(14.4)$ & $7(28.0)$ & & \\
\hline $\mathrm{CC}$ & & & 0 & $1(4.0)$ & & \\
\hline
\end{tabular}

Data are presented as number (\%).

SNP, single nucleotide polymorphism; MAF, minor allele frequency.

${ }^{*}$ Chi-square test with dominant model; ${ }^{\dagger}$ Jonckheere-Terpstra test with allele model. 
Table 4. Odds Ratios of Genotypes in the Peptic Ulcer Group (n=23) and Nonulcer Control Group (n=25)

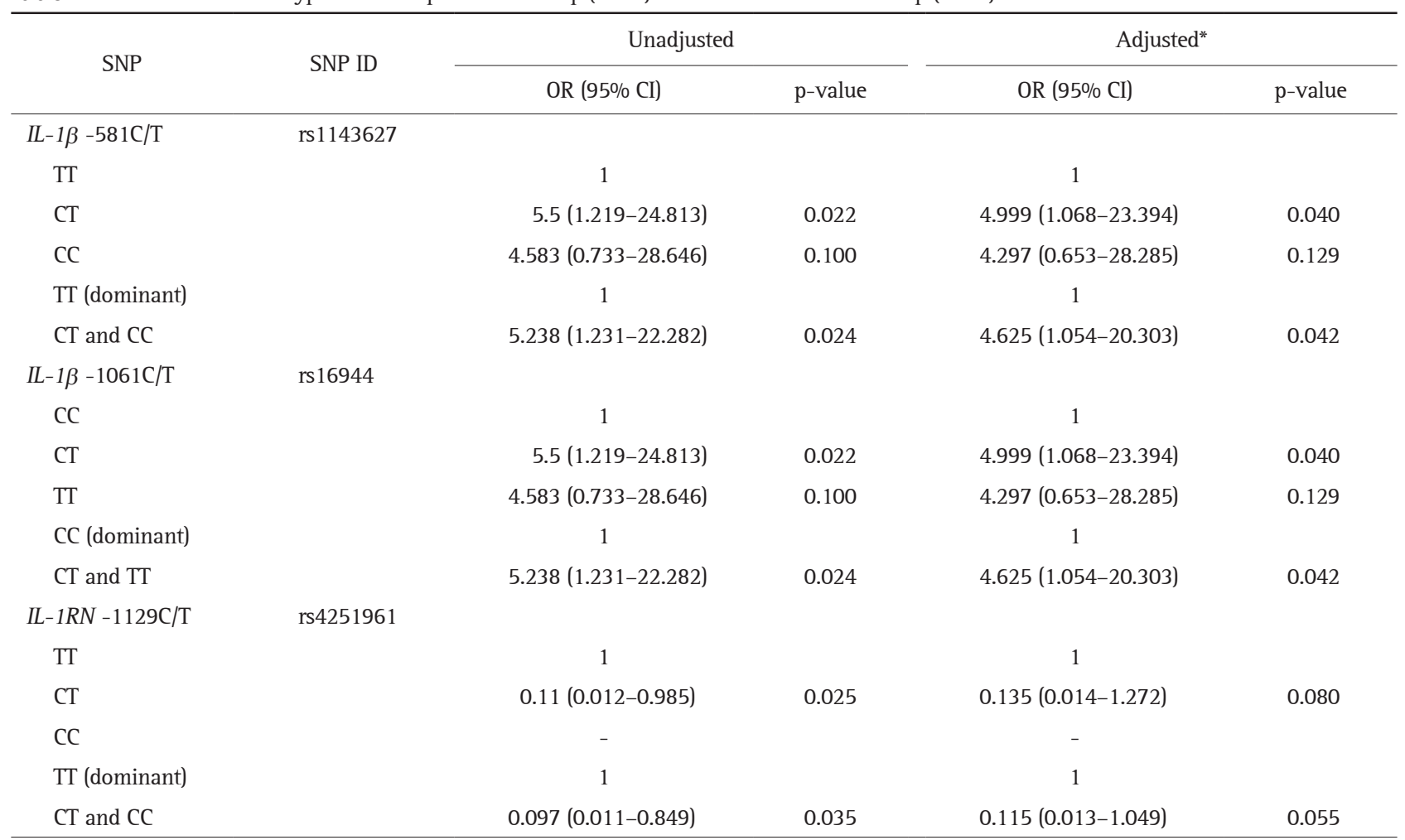

SNP, single nucleotide polymorphism; OR, odds ratio; CI, confidence interval.

*Logistic regression analysis was applied to adjust age and sex.

eventually can result in the development of peptic ulcer. Several SNPs of the COX-1 gene are known to have a significant relationship with peptic ulcer. ${ }^{7,10}$ In U.S. study, two SNPs of COX-1, A-842G and C50T, were found to be associated with aspirin-induced peptic ulcer. ${ }^{7}$ The heterozygous A-842G/C50T haplotype inhibits prostaglandin synthesis by acetylsalicylic acid to a greater degree than does the homozygous haplotype. ${ }^{7}$ However, the opposite results have also been reported for A842G/C50T. ${ }^{11,12}$ A recent systematic review shows no significant association between these SNPs and aspirin resistance. ${ }^{13}$ In addition, different results have been obtained in patients of other races. In Japanese study, the A-842T/C50T polymorphism of the COX-1 gene was not detected in any of the 480 patients studied. ${ }^{6}$ Similarly, this polymorphism was absent in 323 Chinese subjects. ${ }^{14}$ Variable results have been reported within races as well. One study in a Japanese population reported that -1676T alleles of the $C O X-1$ gene promoter were a significant risk factor for NSAID-induced ulcers, ${ }^{6}$ while another Japanese study reported that $-1676 \mathrm{~T}$ alleles are not associated with aspirin-induced peptic ulcer. ${ }^{8}$ In our study, a total of 23 SNPs of the COX1 gene were found, none of which were associated with aspirininduced peptic ulcer.

The biological role of $I L-1 \beta$ is to enhance the inflammatory response, and the cytokine $I L-1 \beta$ induces the expression of other proinflammatory cytokine genes including $T N F-\alpha, I L-2, I L-6$, and $I L-12 .{ }^{15}$ In addition, $I L-1 \beta$ is an inhibitor of gastric acid. ${ }^{15}$ Polymorphisms of $I L-1 \beta-511$ (rs16944) and -31 (rs1143627) have been shown to be significantly associated with aspirininduced peptic ulcer in Japanese patients. ${ }^{8}$ These findings are consistent with those of our study, in which $I L-1 \beta$-1061T (rs16944), which is the same SNP as IL-1 $\beta-511$, was significantly associated with aspirin-induced peptic ulcer. In addition, $I L-1 \beta-581 C$ (rs1143627), which is the same as $I L-1 \beta-31$, was significantly associated with aspirin-induced peptic ulcer. T carriers of $I L-1 \beta-511$ have an associated increased production of $I L-1 \beta$, which enhances inflammation of the gastric mucosa. ${ }^{9,16}$ In our study, T carriers of $I L-1 \beta-1061$ ( $I L-1 \beta-511)$ had a $4.6-$ fold increased risk of low-dose aspirin-induced peptic ulcer. In the future, screening for SNPs of $I L-1 \beta$ prior to initiating aspirin therapy could help to identify patients at high risk for ulcer development and bleeding. These individuals should also be administered a prophylactic proton pump inhibitor, although this assumption requires further investigation.

The IL-1RN gene encodes the IL-1R antagonist (IL-1RA), which exhibits anti-inflammatory properties by competitive inhibition of IL-1 receptors. ${ }^{16,17}$ One study reported that the minor allele of $I L-1 R N-1129$ (rs4251961) is associated with decreased IL-1RA production in healthy adults. ${ }^{17}$ The C allele of $I L-1 R N$ -1129 reduces IL-1RA, which is associated with an increased $I L-1 \beta$ level that in turn inhibits gastric acid secretion. ${ }^{18}$ These 
findings are consistent with our results, in that the TT genotype of $I L-1 R N-1129$ was found in $95.7 \%$ of patients with peptic ulcer, although this was not statistically significant after adjustment for age and sex. Further investigation of $I L-1 R N-1129$ as a potential risk factor for low-dose aspirin-induced peptic ulcer would be valuable.

Our study has several limitations. First, our sample size was too small and thus may not be representative of general genetic trends in the Korean population. In order to find the associations between SNPs and low dose aspirin induced peptic ulcer, we performed the full DNA sequence analysis of these target genes and proposed the several candidates of SNPs related to aspirin induced ulcer. Second, the functional effect of these SNPs are still doubtful. The functional consequences of $I L-1 \beta$ -581C/T (rs1143627) and IL-1 $\beta-1061 \mathrm{C} / \mathrm{T}$ (rs16944) are known to the "upstream variant $2 \mathrm{~KB}$ " (Table 3 ). There is a possibility that they may affect the promoter activity by the differential binding affinity of nuclear proteins, however pathogenic effect of them has not yet been established. Third, the presence of $H$. pylori is questionable in this study. One previous study reported that $H$. pylori infection does not affect peptic ulcer induced by low-dose aspirin $;{ }^{19}$ however, $H$. pylori is regarded as a major cause of peptic ulcer disease and account for a large proportion of peptic ulcers in Korea. Therefore, further investigation including $H$. pylori infection and a functional assay for these SNPs are warranted. Even with these noted limitations, however, this study is the first to investigate the relationships between SNPs and aspirin-induced peptic ulcer in Korean patients, as well as the first to suggest that SNPs may be different according to the population studied.

In conclusion, Korean adults with the the $\mathrm{C}$ allele of $\mathrm{IL}-1 \beta$ $-581 \mathrm{C} / \mathrm{T}$ or the $\mathrm{T}$ allele of $\mathrm{IL}-1 \beta-1061 \mathrm{C} / \mathrm{T}$ had an increased risk of low-dose aspirin-induced peptic ulcer. The polymorphism IL$1 R N-1129$ might also be associated with peptic ulcer, although this trend was not significant. These SNPs may become potential biomarkers for identifying patients at high risk for aspirininduced peptic ulcer, although further investigation and validation are needed.

\section{CONFLICTS OF INTEREST}

No potential conflict of interest relevant to this article was reported.

\section{ACKNOWLEDGEMENTS}

This research was supported by a grant from the Basic Science Research Program through the National Research Foundation of Korea funded by the Ministry of Education, Science, and Technology (number: 2011-0008901). We would like to extend a special thanks to Kyeoung Hee Choi (International Saint Mary's Hospital, Incheon, Korea), Eun-soon Shin, PhD (DNA
Link Inc., Seoul, Korea), and Han-wool Lee (DNA Link Inc.).

\section{REFERENCES}

1. Fujisawa N, Inamori M, Endo $\mathrm{H}$, et al. Incidence of and risk factors for upper gastrointestinal complications in patients taking lowdose aspirin in Japan. Hepatogastroenterology 2011;58:229-234.

2. Yeomans ND, Lanas AI, Talley NJ, et al. Prevalence and incidence of gastroduodenal ulcers during treatment with vascular protective doses of aspirin. Aliment Pharmacol Ther 2005;22:795-801.

3. Scheiman JM, Devereaux PJ, Herlitz J, et al. Prevention of peptic ulcers with esomeprazole in patients at risk of ulcer development treated with low-dose acetylsalicylic acid: a randomised, controlled trial (OBERON). Heart 2011;97:797-802.

4. Shiotani A, Kamada T, Haruma K. Low-dose aspirin-induced gastrointestinal diseases: past, present, and future. J Gastroenterol 2008;43:581-588.

5. Lanas A, Scheiman J. Low-dose aspirin and upper gastrointestinal damage: epidemiology, prevention and treatment. Curr Med Res Opin 2007;23:163-173.

6. Arisawa T, Tahara T, Shibata T, et al. Association between genetic polymorphisms in the cyclooxygenase-1 gene promoter and peptic ulcers in Japan. Int J Mol Med 2007;20:373-378.

7. Halushka MK, Walker LP, Halushka PV. Genetic variation in cyclooxygenase 1: effects on response to aspirin. Clin Pharmacol Ther 2003;73:122-130.

8. Shiotani A, Sakakibara T, Yamanaka Y, et al. The preventive factors for aspirin-induced peptic ulcer: aspirin ulcer and corpus atrophy. J Gastroenterol 2009;44:717-725.

9. Shiotani A, Sakakibara T, Nomura M, et al. Aspirin-induced peptic ulcer and genetic polymorphisms. J Gastroenterol Hepatol 2010;25 Suppl 1:S31-S34.

10. Maree AO, Curtin RJ, Chubb A, et al. Cyclooxygenase-1 haplotype modulates platelet response to aspirin. J Thromb Haemost 2005;3: 2340-2345.

11. Pettinella C, Romano M, Stuppia L, Santilli F, Liani R, Davì G. Cyclooxygenase-1 haplotype C50T/A-842G does not affect platelet response to aspirin. Thromb Haemost 2009;101:687-690.

12. van Oijen MG, Laheij RJ, Koetsier M, et al. Effect of a specific cyclooxygenase-gene polymorphism (A-842G/C50T) on the occurrence of peptic ulcer hemorrhage. Dig Dis Sci 2006;51:23482352

13. Goodman T, Ferro A, Sharma P. Pharmacogenetics of aspirin resistance: a comprehensive systematic review. Br J Clin Pharmacol 2008;66:222-232.

14. Li Q, Chen BL, Ozdemir V, et al. Frequency of genetic polymorphisms of COX1, GPIIIa and P2Y1 in a Chinese population and association with attenuated response to aspirin. Pharmacogenomics 2007;8:577-586

15. El-Omar EM. The importance of interleukin 1beta in Helicobacter pylori associated disease. Gut 2001;48:743-747.

16. El-Omar EM, Carrington M, Chow WH, et al. Interleukin-1 poly- 
368 Gut and Liver, Vol. 10, No. 3, May 2016

morphisms associated with increased risk of gastric cancer. Nature 2000;404:398-402.

17. Carrol ED, Payton A, Payne D, et al. The IL1RN promoter rs4251961 correlates with IL-1 receptor antagonist concentrations in human infection and is differentially regulated by GATA-1. J Immunol 2011;186:2329-2335.

18. Rafiq S, Stevens K, Hurst AJ, et al. Common genetic variation in the gene encoding interleukin-1-receptor antagonist (IL-1RA) is associated with altered circulating IL-1RA levels. Genes Immun 2007;8:344-351.

19. Shiotani A, Murao T, Sakakibara T, et al. Association of SLCO1B1 $1 \mathrm{~b}$ with peptic ulcer amongst Japanese patients taking low-dose aspirin. Dig Liver Dis 2012;44:201-205. 